\title{
The relationship between HAART use and sexual activity among HIV-positive women of reproductive age in Brazil, South Africa, and Uganda
}

\author{
A. KAIDA $^{1,2}$, G. GRAY ${ }^{3}$, F. I. BASTOS 4 , I. ANDIA ${ }^{5}$, M. MAIER ${ }^{6}$, J. MCINTYRE $^{3}$, \\ B. GRINSZTEJN ${ }^{4}$, S. A. STRATHDEE ${ }^{7}$, D. R. BANGSBERG ${ }^{6}$, \& R. $\mathrm{HOGG}^{2,8}$ \\ ${ }^{1}$ Department of Healthcare and Epidemiology, Faculty of Medicine, University of British Columbia, Vancouver, Canada, ${ }^{2} B C$ \\ Centre for Excellence in HIVIAIDS, Vancouver, Canada, ${ }^{3}$ Perinatal HIV Research Unit, the University of Witwatersrand, \\ Soweto, South Africa, ${ }^{4}$ The Oswaldo Cruz Foundation, FIOCRUZ, Rio de Faneiro, Brazil, ${ }^{5}$ Mbarara University of Science \\ and Technology, Mbarara, Uganda, ${ }^{6}$ University of California, San Francisco, California, US, ${ }^{7}$ Division of International \\ Health and Cross-Cultural Medicine, Department of Family and Preventive Medicine, University of California, San Diego, \\ US, and ${ }^{8}$ Faculty of Health Sciences, Simon Fraser University, Burnaby, British Columbia, Canada
}

\begin{abstract}
The purpose of this study was to determine whether current HAART use is associated with recent sexual intercourse among HIV-infected women (18-49 years) from Brazil, South Africa and Uganda. We conducted an analysis of survey data from a cross-sectional study, which enrolled $179 \mathrm{HIV}$-infected women receiving regular care from the Mbarara Hospital HIV Clinic in Uganda $(n=85)$; the Perinatal HIV Research Unit in Soweto, South Africa $(n=50)$; and the IPEC-Fiocruz cohort in Rio de Janeiro, Brazil $(n=44)$. The primary outcome was sexual intercourse in the previous month. Secondary outcomes were protected sex and contraceptive use. We found that overall, 46\% reported recent sexual intercourse. After adjusting for covariates, recent sexual intercourse was not associated with HAART use (AOR: 0.76; 95\% CI: 0.34-1.72); however, it was significantly associated with being currently married, wanting to have more children and having higher HAART optimism. Among women reporting recent sexual intercourse $(n=83)$, HAART users were significantly more likely to practice protected sex (crude OR: 3.64; 95\% CI: 1.41-9.38) and non-significantly more likely to use contraceptive methods (crude OR: 2.15; 95\%CI: 0.77-5.99). In summary, self-reported recent sexual intercourse is not more likely among women on HAART. Moreover, sexually active HAART users may be more likely to practice protected sex and use contraceptives.
\end{abstract}

\section{Introduction}

The vast majority of the world's 14 million HIVinfected women live in developing and transitional countries where sexual contact is the primary mode of HIV transmission (UNAIDS, 2006). A growing body of evidence from such countries reveals that antiretroviral therapy has dramatically improved the survival and quality of life for HIV-infected individuals (Marins et al., 2003; Seyler et al., 2003; Spacek et al., 2006; Wools-Kaloustian et al., 2006). Recent global efforts to improve access to highly active antiretroviral therapy (HAART) and clinical care should serve to deliver these positive outcomes to more HIV-infected women in high prevalence and low-resource settings (World Health Organization [WHO], 2004).

In addition to the anticipated clinical effects, HAART use may influence the sexual behaviour of HIV-infected women. Earlier research demonstrated that in the absence of treatment, HIV-infected women were less sexually active than HIV-negative women owing, in part, to higher morbidity (Gray et al., 1998; Wilson et al., 1999). The health improvements associated with the use of HAART are anticipated to increase sexual activity due to improved health status (Kaida et al., 2006) and perceptions of reduced infectivity (Kalichman et al., 2001), however, related empirical evidence is lacking.

Given the close relationship between sexual transmission of HIV and the incidence of pregnancy, information about the sexual behaviours of HIVpositive women on HAART constitute a critical component of comprehensive initiatives aimed at improving the quality of life of HIV-infected women, including sexual and reproductive decision-making.

The purpose of this study was to determine whether current HAART use is associated with recent sexual 
intercourse among HIV-infected women of reproductive age (18-49 years) from Brazil, South Africa and Uganda. A secondary purpose was to estimate differences in protected sex and contraceptive use among sexually active HAART users and non-users.

\section{Methods}

\section{Study design}

This analysis is based on data collected from a crosssectional survey conducted in Brazil, South Africa and Uganda. The primary outcome was recent sexual activity, defined as vaginal intercourse in the previous month. The secondary outcomes were protected vaginal intercourse (defined as 'always used a condom') and contraceptive use in the previous six months. The key explanatory variable was current HAART use.

The study was conceived as a pilot project to determine the feasibility of conducting a longitudinal study among a larger sample of HIV-positive women in Brazil, South Africa and Uganda.

\section{Study setting and sample population}

A total of 179 HIV-positive women in patient care were randomly selected for participation through the Mbarara Hospital HIV Clinic in Mbarara, Uganda $(n=85)$; the Perinatal HIV Research Unit in Soweto, South Africa $(n=50)$; and the IPECFiocruz cohort in Rio de Janeiro, Brazil $(n=44)$ (Grinsztejn et al., 2006).

Eligible women had to have documented HIV status, be of reproductive age (defined as 18-49 years) and be seeking regular care at one of the three study centres.

\section{Data collection}

A consecutive sample of HIV-positive women accessing services at each study site was selected to participate. A study representative explained the study purpose, procedures, risks and benefits as part of the informed consent process. Participation rates exceeded $90 \%$ in each of the study sites.

Upon identification and consent, study participants responded to an interviewer-administered questionnaire in either English or the local language. Measures included: sociodemographics; HIV/AIDS history, diagnosis and treatment; self-reported health; sexual and contraceptive behaviour; fertility desires; and HAART optimism (a 13-item scale yielding a range of scores from 13-52, with higher scores indicating greater optimism) (Van de Ven et al., 2000).

The interviewers at each study site were women from the local community. They were trained in survey research, including instruction on how to conduct an interview and how to obtain informed consent. Data collection took place between March and June 2005.

\section{Data analysis}

We compared the prevalence of recent sexual intercourse across groups (i.e. sexually active nonHAART users versus sexually active HAART users). Unadjusted odds ratios (OR) and 95\% confidence intervals $(95 \% \mathrm{CI})$ were computed to determine the magnitude of the association between independent variables and recent sexual intercourse.

Multivariate logistic regression was used to model the association between HAART use and the likelihood of recent sexual intercourse, while controlling for covariates. All independent variables were tested for colinearity. It was suspected a priori that the variables 'marital status' and 'HIV-infected partner/ spouse' would be highly associated and this was empirically confirmed. Therefore, only 'marital status' was considered for entry into the multivariate model. To yield adjusted odds ratios (AOR) and $95 \% \mathrm{CI}$, a stepwise procedure was used to enter HAART use and all variables significant in the univariate analysis into a logistic regression model (Hosmer \& Lemeshow, 2000). The variables 'country' and 'age' were forced into the model to obtain adjusted estimates of effect.

\section{Prevalence of contraceptive use and protected sexual activity}

Among women reporting recent sexual intercourse, we compared the proportion that report using condoms (i.e. 'protected sex') and contraceptives between HAART users and non-users. Crude ORs and $95 \% \mathrm{CIs}$ were computed to determine the magnitude of the association between HAART use and protected sex and contraceptive use. Given that this was a secondary objective of the analysis and owing to the small sample size, multivariate analysis was not conducted for these two outcome variables.

All statistical tests are two-sided and considered significant at $\alpha=0.05$. Statistical analyses were done using SAS for Windows (version 9.1) (The SAS Institute, 2005).

\section{Ethical considerations}

Ethics approval for this study was obtained from the Human Research Ethics Committee (Medical) of the University of the Witwatersrand in Johannesburg, South Africa; the Faculty of Medicine Research and Ethics Committee and the Institutional Ethics Review Board of Mbarara University; 
and the local and national Institutional Review Boards (IRBs) in Brazil. Study investigators only had access to de-identified data.

\section{Results}

Overall, $46 \%$ of the participants reported sexual intercourse in the previous month (83/179). By study site, $33 \%$ of women in Uganda, $55 \%$ of women in Brazil and $62 \%$ of women in South Africa reported recent sexual intercourse.

\section{Baseline characteristics}

Distributions of baseline covariates are presented in Table I. Nearly two-thirds (65\%) of women reported currently using HAART (56\% in Uganda, $64 \%$ in Brazil, and $80 \%$ in South Africa). The mean age of women was 34.5 years $(\mathrm{SD}=6.9)$. Only $22 \%$ were employed full-time and the mean years of formal schooling was $7.2(\mathrm{SD}=4.0)$. Thirty-four percent were currently married and nearly one-third (32\%) reported knowing that their primary partner/spouse was HIV-infected. Sixty-eight percent reported having been diagnosed with AIDS, however, 66\% reported their current health status as 'excellent, very good, or good' and the mean HAART optimism score was $30(\mathrm{SD}=6.7)$. The majority of women did not want any (more) children $(65 \%)$.

\section{Univariate analyses}

Women on HAART were just as likely as women not on HAART to report recent sexual intercourse (OR: 0.93; 95\%CI: $0.50-1.71$ ) (Table II). Women who reported recent sexual intercourse were, however, more likely to have higher HAART optimism scores, have more education, be currently married, have an HIV-positive primary partner/spouse, desire more children and not have been diagnosed with AIDS.

\section{Adjusted analyses}

After adjusting for potential confounders, there remained no association between HAART use and recent sexual activity (AOR: 0.76; 95\%CI: 0.34 1.72) (see Table II). Being currently married, desiring more children and having a higher HAART optimism score remained most strongly associated with recent sexual intercourse.

\section{Contraceptive use and protected sexual activity}

Of the 83 women reporting recent sexual intercourse, $76 \%$ were using contraceptive methods and $63 \%$ were engaging in protected sex (i.e. using condoms). Women using HAART were significantly more likely to practice protected sex (crude OR:
Table I. Baseline characteristics of study population: HIV-infected women of reproductive age in Brazil, South Africa and Uganda $(n=179)$.

\begin{tabular}{|c|c|c|}
\hline Characteristic & Frequency $(\mathrm{n})$ & $(\%)$ \\
\hline \multicolumn{3}{|l|}{ Country } \\
\hline South Africa & 50 & 28 \\
\hline Uganda & 85 & 48 \\
\hline Brazil & 44 & 25 \\
\hline \multicolumn{3}{|l|}{ Sociodemographic variables } \\
\hline Mean age $(\mathrm{SD})$ & \multicolumn{2}{|l|}{$34.5(6.9)$} \\
\hline Mean years of schooling (SD) & \multicolumn{2}{|l|}{$7.2(4.0)$} \\
\hline \multicolumn{3}{|l|}{ Employed full time } \\
\hline Yes & 39 & 22 \\
\hline No & 139 & 78 \\
\hline \multicolumn{3}{|l|}{ Marital status } \\
\hline Currently married & 61 & 34 \\
\hline Not currently married & 118 & 66 \\
\hline \multicolumn{3}{|l|}{$\begin{array}{l}\text { Fertility desire \& health status variables } \\
\text { Want more children? }\end{array}$} \\
\hline Yes & 62 & 35 \\
\hline No & 117 & 65 \\
\hline \multicolumn{3}{|l|}{ Self-reported health status } \\
\hline Excellent, very good or good & 116 & 66 \\
\hline Fair or poor & 61 & 35 \\
\hline \multicolumn{3}{|l|}{ HIV-infection related variables } \\
\hline Yes & 57 & 32 \\
\hline No or unknown & 122 & 68 \\
\hline \multicolumn{3}{|l|}{ AIDS diagnosis } \\
\hline Yes & 122 & 68 \\
\hline No or unknown & 57 & 32 \\
\hline \multicolumn{3}{|l|}{ Current HAART use } \\
\hline Yes & 116 & 65 \\
\hline No & 63 & 35 \\
\hline Mean HAART optimism score (SD) & $30(6.7)$ & \\
\hline
\end{tabular}

3.64; 95\%CI: 1.41-9.38) and non-significantly more likely to use contraceptive methods (crude OR: 2.15; 95\% CI: 0.77-5.99) than non-users.

\section{Discussion}

We found that, among HIV-infected women in Brazil, South Africa and Uganda, HAART users and non-users were equally likely to report recent sexual intercourse. This finding is consistent with other reports of HIV-infected men and women in Uganda (Bateganya et al., 2005; Bunnell et al., 2006) and Côte d'Ivoire (Moatti et al., 2003).

In sub-analyses, we investigated the association between HAART use and recent sexual activity for each country. While the effect of sociodemographic covariates varied, none of the country-specific models showed a significant relationship between HAART use and recent sexual activity.

Recent sexual activity among HIV-positive women in our study appears to be most strongly influenced by factors unrelated to HAART use, including being currently married and wanting more children. This 
Table II. Unadjusted and adjusted ORs and 95\%CI of variables associated with recent sexual intercourse (in the previous month) among HIV-infected women in Brazil, South Africa and Uganda $(n=179)$.

\begin{tabular}{|c|c|c|c|c|}
\hline \multirow[b]{2}{*}{ Characteristic } & \multicolumn{2}{|c|}{ Sexual intercourse in the past month } & \multirow{2}{*}{$\begin{array}{l}\text { Unadjusted OR } \\
\qquad(95 \% \mathrm{CI})\end{array}$} & \multirow{2}{*}{$\begin{array}{l}\text { Adjusted OR* } \\
\quad(95 \% \mathrm{CI})\end{array}$} \\
\hline & Yes $(n=83)$ & No $(n=96)$ & & \\
\hline \multicolumn{5}{|l|}{ Country (\%) } \\
\hline Brazil & 29 & 21 & Reference & - \\
\hline Uganda & 37 & 20 & $1.36(0.60-3.10)$ & \\
\hline South Africa & 34 & 59 & $0.41(0.19-0.86)$ & \\
\hline \multicolumn{5}{|l|}{ Sociodemographic variables } \\
\hline Age (Mean [SD]) & $33.8(6.4)$ & $35.1(7.2)$ & $0.97(0.93-1.02)$ & - \\
\hline Years of Schooling (Mean [SD]) & $8.2(3.5)$ & $6.4(4.3)$ & $1.12(1.04-1.21)$ & - \\
\hline Employed full-time (\%) & & & $1.70(0.83-3.49)$ & - \\
\hline Yes & 27 & 18 & & \\
\hline No & 73 & 82 & & \\
\hline Marital status (\%) & & & $3.71(1.93-7.14)$ & $6.68(2.79-16.0)$ \\
\hline Currently married & 49 & 21 & & \\
\hline Not currently married & 51 & 79 & & \\
\hline \multicolumn{5}{|l|}{ Fertility desire \& health status variables } \\
\hline Want more children? $(\%)$ & & & $3.89(2.02-7.49)$ & $4.09(1.71-9.81)$ \\
\hline Yes & 51 & 21 & & \\
\hline No & 49 & 79 & & \\
\hline Self-reported health status (\%) & & & $1.49(0.80-2.80)$ & - \\
\hline Excellent, very good or good & 70 & 61 & & \\
\hline Fair or Poor & 30 & 39 & & \\
\hline \multicolumn{5}{|l|}{ HIV-infection related variables } \\
\hline HIV-infected partner/spouse (\%) & & & $4.32(2.19-8.52)$ & - \\
\hline Yes & 48 & 18 & & \\
\hline No or unknown & 52 & 82 & & \\
\hline AIDS diagnosis (\%) & & & $0.37(0.19-0.70)$ & - \\
\hline Yes & 57 & 78 & & \\
\hline No or unknown & 43 & 22 & & \\
\hline HAART use (\%) & & & $0.93(0.50-1.71)$ & $0.76(0.34-1.72)$ \\
\hline Yes & 64 & 66 & & \\
\hline No & 36 & 34 & & \\
\hline $\begin{array}{l}\text { HAART optimism score } \\
\text { (Mean [SD]) }\end{array}$ & $31.3(6.1)$ & $27.8(6.8)$ & $1.09(1.03-1.14)$ & $1.11(1.04-1.17)$ \\
\hline
\end{tabular}

*Adjusted odds ratios obtained from a stepwise procedure to choose a logistic regression model with forced entry of the variables 'age' and 'country'.

finding was expected based on the literature on predictors of sexual activity and coital frequency among women in general (Bongaarts \& Potter, 1983; Rao \& Demaris, 1995). Interestingly, HAART optimism was also associated with recent sexual activity suggesting that being optimistic about the benefits of HAART is a better predictor of recent sexual intercourse than HAART use itself. It is difficult to compare these findings since the vast majority of literature on the impact of HAART optimism comes from populations of men who have sex with men in resource-rich areas (Abelson et al., 2006; Sullivan et al., 2006).

Of note, while HAART use wasn't associated with recent sexual intercourse overall, it was positively associated with other sexual behaviours, including protected sex and contraceptive use. Recently, others have similarly reported that HAART users in developing countries are more likely to practice protected sex (Bateganya et al., 2005; Bunnell et al., 2006; Moatti et al., 2003), however, there is limited comparative literature on the impact of HAART on contraceptive use.

The relatively small sample size and the diversity of the countries involved may constitute important limitations to this study. These features of the study design are a consequence of conducting a pilot study. Presently, however, larger, separate studies are being conducted in each of the three study settings to further verify the results presented here.

In conclusion, this study supports an absence of association between HAART use and recent sexual intercourse. Sexually active HAART users may, however, be more likely to practice protected sex and use contraceptives. This information is important for the development of family planning services for HIVinfected women. 


\section{Acknowledgements}

We would like to thank the research and clinical staff at the Mbarara Hospital HIV Clinic, the University of Science and Technology, the Perinatal HIV Research Unit in Soweto and the IPEC-FIOCRUZ cohort in Rio de Janeiro for their assistance with this research. Funding and support was provided by NIMH 54907, AA015287, the Doris Duke Charitable Foundation, the Ford Foundation (Brazil office) and FIOCRUZ.

\section{References}

Abelson, J., Rawstorne, P., Crawford, J., Mao, L., Prestage, G., \& Kippax, S. (2006). HIV optimism does not explain increases in high-risk sexual behaviour among gay men of positive or negative HIV status in Sydney, Australia. AIDS, 20, 12151216.

Bateganya, M., Colfax, G., Shafer, L.A., Kityo, C., Mugyenyi, P., Serwadda, D., et al. (2005). Antiretroviral therapy and sexual behavior: A comparative study between antiretroviral-naive and -experienced patients at an urban HIV/AIDS care and research center in Kampala, Uganda. AIDS Patient Care and STDs, 19, 760-768.

Bongaarts, J., \& Potter, R.G. (1983). Fertility, biology and behaviour: An analysis of the proximate determinants. New York, NY: Academic Press.

Bunnell, R., Ekwaru, J.P., Solberg, P., Wamai, N., BikaakoKajura, W., Were, W., et al. (2006). Changes in sexual behavior and risk of HIV transmission after antiretroviral therapy and prevention interventions in rural Uganda. AIDS, 20, 85-92.

Gray, R.H., Wawer, M.J., Serwadda, D., Sewankambo, N., Li, C., Wabwire-Mangen, F., et al. (1998). Population-based study of fertility in women with HIV-1 infection in Uganda. Lancet, 351, 98-103.

Grinsztejn, B., Bastos, F.I., Veloso, V.G., Friedman, R.K., Pilotto, J.H., Schechter, M., et al. (2006). Assessing sexually transmitted infections in a cohort of women living with HIV/AIDS in Rio de Janeiro, Brazil. International fournal of STD $\&$ AIDS, 17, 473-478.

Hosmer, D.W., \& Lemeshow, S. (2000). Applied logistic regression. New York, NY: Wiley.

Kaida, A., Andia, I., Maier, M., Strathdee, S.A., Bangsberg, D.R., Spiegel, J., et al. (2006). The potential impact of antiretroviral therapy on fertility in sub-Saharan Africa. Current HIV/AIDS Reports, 3, 177-184.
Kalichman, S.C., Rompa, D., Austin, J., Luke, W., \& DiFonzo, K. (2001). Viral load, perceived infectivity and unprotected intercourse. Fournal of Acquired Immune Deficiency Syndromes, 28, 303-305.

Marins, J.R., Jamal, L.F., Chen, S.Y., Barros, M.B., Hudes, E.S., Barbosa, A.A., et al. (2003). Dramatic improvement in survival among adult Brazilian AIDS patients. AIDS, 17, 1675-1682.

Moatti, J.P., Prudhomme, J., Traore, D.C., Juillet-Amari, A., Akribi, H.A., Msellati, P., et al. (2003). Access to antiretroviral treatment and sexual behaviours of HIV-infected patients aware of their serostatus in Cote d'Ivoire. AIDS, 17(Suppl. 3), S69S77.

Rao, K.V., \& Demaris, A. (1995). Coital frequency among married and cohabiting couples in the US. Fournal of Biosocial Science, 27, 135-150.

Seyler, C., Anglaret, X., Dakoury-Dogbo, N., Messou, E., Toure, S., Danel, C., et al. (2003). Medium-term survival, morbidity and immunovirological evolution in HIV-infected adults receiving antiretroviral therapy, Abidjan, Cote d'Ivoire. Antiviral Therapy, 8, 385-393.

Spacek, L.A., Shihab, H.M., Kamya, M.R., Mwesigire, D., Ronald, A., Mayanja, H., et al. (2006). Response to antiretroviral therapy in HIV-infected patients attending a public, urban clinic in Kampala, Uganda. Clinical infectious diseases, 42, 252-259.

Sullivan, P.S., Drake, A.J., \& Sanchez, T.H. (2007). Prevalence of treatment optimism-related risk behavior and associated factors among men who have sex with men in 11 states, 2000-2001. AIDS and behaviour, 11, 123-129.

The SAS Institute (2005). SAS (computer program). Cary, NC: The SAS Institute.

UNAIDS (2006). AIDS epidemic update: December 2005. Geneva, Switzerland: UNAIDS/WHO.

Van de Ven, P., Crawford, J., Kippax, S., Knox, S., \& Prestage, G. (2000). A scale of optimism-scepticism in the context of HIV treatments. AIDS Care, 12, 171-176.

Wilson, T.E., Massad, L.S., Riester, K.A., Barkan, S., Richardson, J., Young, M., et al. (1999). Sexual, contraceptive and drug use behaviors of women with HIV and those at high risk for infection: Results from the women's interagency HIV study. AIDS, 13, 591-598.

Wools-Kaloustian, K., Kimaiyo, S., Diero, L., Siika, A., Sidle, J., Yiannoutsos, C.T., et al. (2006). Viability and effectiveness of large-scale HIV treatment initiatives in sub-Saharan Africa: Experience from western Kenya. AIDS, 20, 41-48.

WHO (2004). ' 3 by 5' progress report. Geneva, Switzerland: UNAIDS/WHO. 
Copyright of AIDS Care is the property of Routledge and its content may not be copied or emailed to multiple sites or posted to a listserv without the copyright holder's express written permission. However, users may print, download, or email articles for individual use. 